\title{
BIOFÍSICA DA VISÃO: GLAUCOMA, ASTIGMATISMO E MIOPIA
}

\author{
Leidiane Batista Gonçalves ${ }^{1}$ \\ Méjane Cristina Portela Vaz ${ }^{2}$ \\ Lelis Araújo de Oliveira ${ }^{3}$
}

RESUMO: Cerca de 2,2 milhões de pessoas não enxergam direito no mundo por terem problemas de visão relacionados à miopia (25\%), astigmatismo (70\%) e glaucoma (2\%). A visão, assim como a audição, faz parte do sistema sensorial, o qual situa aqueles que o possue em relação com o mundo ao seu redor, sendo ativo pelas sinapses do cérebro e projetados pelo globo ocular. Segundo artigos publicados por Empresas Americanas de Saúde os problemas de visão acontecem com maior frequência em adultos a partir de 40 anos e com a pré-disposição em negros por conta do excesso de pigmentação. O objetivo do presente trabalho é verificar através de um questionário estruturado qual o tipo de relação existente entre as doenças citadas (glaucoma, astigmatismo e miopia) com a cor da pele e idade de cada indivíduo. Almejamos com esse trabalho contribuir para os estudos a respeito desta relação, uma vez que existem poucas pesquisas relacionadas ao tema de biofísica da visão.

Palavras-chave: Alteração. Cegueira. Diagnóstico. Doença. Olhos.

ABSTRACT: About 2.2 million people worldwide are blind due to vision problems related to myopia (25\%), astigmatism (70\%) and glaucoma (2\%). Vision, like hearing, is part of the sensory system, which places those who have it in relation to the world around them, being active by the synapses of the brain and projected by the eyeball. According to articles published by American Health Companies, vision problems occur more frequently in adults over 40 years of age and with a predisposition in blacks due to excess pigmentation. The objective of the present work is to verify, through a structured questionnaire, what type of relationship exists between the aforementioned diseases (glaucoma, astigmatism and myopia) with the skin color and age of each individual. With this work, we aim to contribute to studies about this relationship, since there are few researches related to the biophysics of vision.

Keywords: Alteration. Blindness. Diagnosis. Disease. Eyes.

\footnotetext{
${ }^{1}$ Graduação em Letras pela Faculdades Integradas Ipiranga(2016).

${ }^{2}$ Graduanda em Ciências Biológicas pelo Instituto Federal do Pará e graduando em Educação Física pelo Instituto Claretiano. E-mail: mejanevaz@gmail.com

${ }^{3}$ Doutorado em Engenharia Elétrica com ênfase em Telecomunicações pela Universidade Federal do Pará. Mestrado em Geofísica Universidade Federal do Pará. Licenciado Pleno em Física- UFPA Especialista em Ensino de Física- Universidade Federal do Pará.
} 


\section{INTRODUÇÃO}

Os olhos tem a capacidade de perceber os estímulos luminosos e converter a energia luminosa em energia química, o qual é formado basicamente por: córnea, íris, pupila, cristalino, retina, esclera e nervo óptico, onde os raios luminosos são transformados em impiulsos nervosos, de modo a chegarem através das vias visuais ao cérebro, local onde a informação é descodificada e onde as imagens visualizadas são elaboradas. Segundo a OMS (Organização Mundial da Saúde), cerca de 2,2 bilhões de pessoas sofrem com situações oculares mais diversas e os diagnósticos oferecidos trabalham diretamente com a física, desde os equipamentos (feitos de nanotecnologia para melhor precisão dos resultados), quanto os tratamentos usando lentes que interferem na refração ocular. Depois de passar dos 40 anos o paciente poderá perceber que fica mais difícil focar em objetos de perto, isso ocorre porque a lente no interior do olho começa perder sua capacidade de mudar de formato, chamado de "vista cansada". Em vista disso, na deficiência visual vamos ter duas categorias: a cegueira e a

baixa visão. Para SÁ, CAMPOS E SILVA (2007) “A cegueira é uma alteração grave ou total da visão, afetando a capacidade de perceber cor, tamanho, distância, forma, posição ou movimento. Já a baixa visão é uma grave perda visual, ou seja, é a redução da acuidade visual. Assim, a cegueira pode ser apresentada desde o nascimento (cegueira congênita) ou em decorrência de causas orgânicas ou acidentais (cegueira adquirida)." Já (GRANZOTO et al.,2003) "Estima-se que cerca de 7,5 milhões de crianças em idade escolar sejam portadoras de algum tipo de deficiência visual e apenas $25 \%$ delas apresentam sintomas." Para (SILVA et al.,2013)"Sabe-se que no Brasil 10\% dos escolares necessitam de correção visual por serem portadores de erros de refração como: hipermetropia, miopia e astigmatismo, sendo que destes, aproximadamente $5 \%$ tem redução grave de acuidade visual, isto é, menos de $50 \%$ da visão normal." Temos nessa pesquisa o objetivo de verificar através de análises feitas no questionário estruturado que tipo de relação existe entre as doenças oculares citadas com a cor da pele e idade das pessoas e se a eficácia dos tratamentos são iguais independente da idade ou etnia do paciente. Espera-se que ao final da averiguação 
dos questionários, haja uma contribuição para novos estudos a respeito desta relação entre problemas oculares, idade e etnia, e que ocorra um melhor aprofundamentos em estudos científicos, já que são temas dificéis de se encontrar para estudo.

\section{MATERIAL E MÉTODOS}

Para alcançar o objetivo do trabalho realizamos uma pesquisa em duas escolas municipais e duas estaduais entre os meses de dezembro a janeiro, com a utilização de questionário estruturado e uma pesquisa qualitativa e quantitativa, a fim de ratificar as problemáticas da Biofísica da Visão. Foram feitas cinco perguntas para cada entrevistado, essa pesquisa ocorreu no município de Abaetetuba/ $\mathrm{Pa}$, onde participaram trinta pessoas, do sexo masculino e feminino com diferenças em idade e cor para compreender as variações das doenças visuais citadas.

\section{RESULTADOS E DISCUSSÃO}

Concluí-se que as dificuldades na visão precisam de cuidados especiais já que representam comoprometimento do canal sensorial mais importante na aquisição de informações com consequências sobre o desenvolvimento. Ao finalizar os estudos sobre a abordagem do questionário estruturado, tivemos um percetual em forma de gráfico o qual comprova que pessoas acima dos 40 anos e da cor negra tem maior índice de doenças visuais. A análise mostrou que predominou questões relacionadas à maior idade e a pigmentação elevada de pele, e com menores índices foram os de idades abaixo de 30 anos e pele clara.

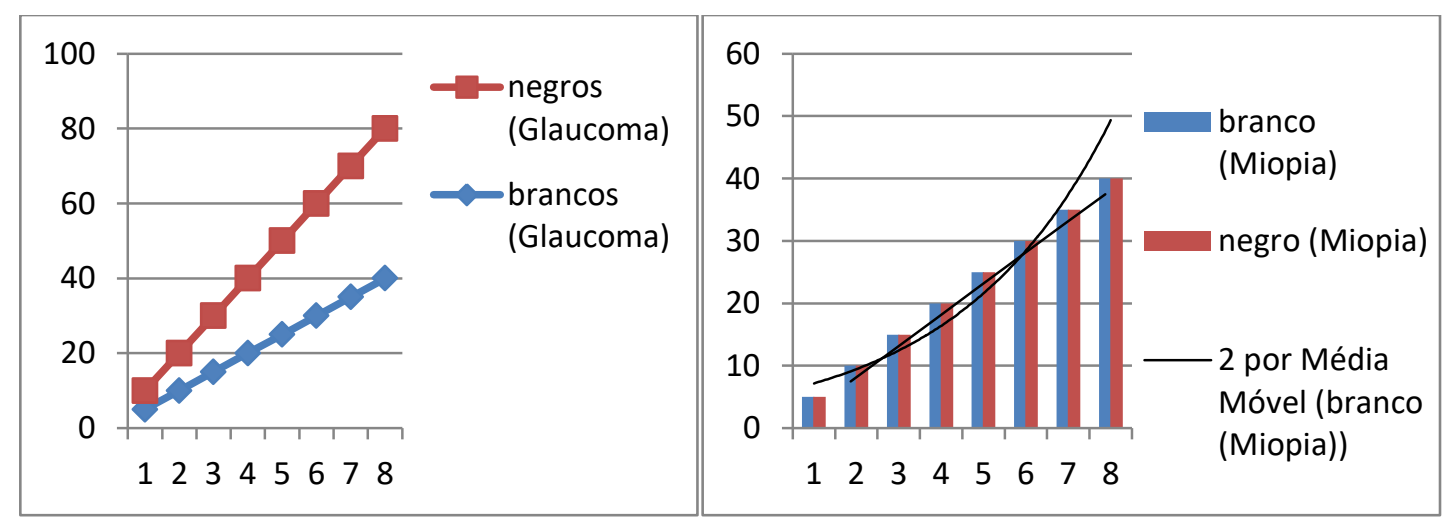




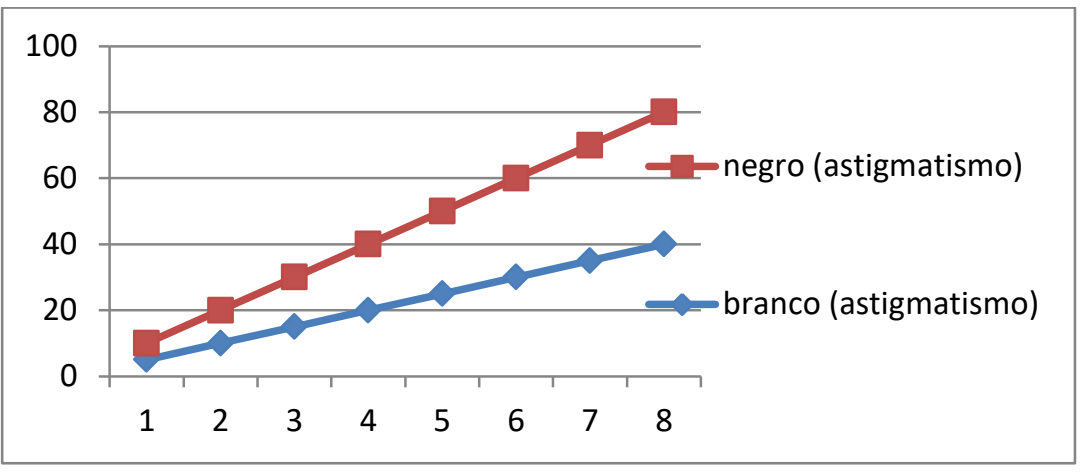

\section{CONSIDERAÇÕES FINAIS}

Em vista dos argumentos apresentados anteriormente, nos preocupamos em buscar informações sobre os principais problemas da visão humana, dentre eles o astigmatismo, glaucoma e miopia. Nos questionários observamos que a etnia e a idade são os principais fatores que contribuem para o desenvolvimento de problemas visuais, mas que outros fatores exógenos interferem nesses problemas que afetam a visão da população. Para atenuar essa problemática é necessário um tratamento precoce, como a busca de atendimentos e procedimentos oftalmológicos, sejam eles por meio do uso de lentes ou de cirurgias a lazer.

\section{AGRADECIMENTOS}

Agradecemos primeiramente a Deus, o autor de nossas vidas, em segundo plano ao Doutor Lelis Araujo de Oliveira nosso orientador, pela paciência, compreensão e dedicação nas atribuições de seu trabalho enquanto professor.

\section{REFERÊNCIAS BIBLIOGRÁFICAS}

https://drauziovarella.uol.com.br/doencas-e-sintomas/miopia-e-astigmatismo/ https://www.minhavida.com.br/saude/temas/glaucoma

https://veja.abril.com.br/saude/miopes-tem-2-vezes-mais-chances-de-sofrerdeglaucoma/ 